\title{
Comparison of Vibration Threshold of Upper Limb During Upper Limb Neurodynamic Test 1 in Individuals with and without Type II Diabetes Mellitus
}

\author{
RAVI SHANKAR REDDY \\ Department of Medical rehabilitation, College of Applied Medical Sciences, King \\ Khalid University, Kingdom of Saudi Arabia \\ Email: rshankar@kku.edu.sa
}

Received: January 12, 2017| Revised: February 21, 2017| Accepted: March 20, 2017

Published online: April 10, 2017

The Author(s) 2017. This article is published with open access at www .chitkara.edu. in/Publications

\begin{abstract}
Background: Patients withType II diabetes mellitus are showed to affect the sensory, reflex and motor systems in distal extremities. Studies have examined the mechanosensitivity and vibration threshold (VT) in type II diabetes mellitus patients in the lower limb and compared it with normal individuals. There is scanty literature available in comparison of the VTin the upper limb in type II diabetes mellitus patients with non-diabetic individuals.
\end{abstract}

Methods: Thirty type II diabetic individuals (age $-55.60 \pm 9.79$ years)and 30 asymptomatic individuals (age $-53.43 \pm 9.96$ ) without diabetes mellitus participated in the study. Tester at the baseline for both the groups using a bioesthesiometer measured VT. Bioesthesiometer is capable of deriving a vibration of $100 \mathrm{~Hz}$. Following VTevaluation at the baseline, the tester performed the ULNT1 for all the subjects. During the sequence of the ULNT1, VTwas measured at initial onset of pain (termed as P1) and short of maximum pain (P2) as experienced by the patient.

Results:There was a statistical significant difference inVTbetween diabetic and non-diabetic group subjects. VTwas raised in the diabetic group at all the three levelsof evaluation (baseline, P1 and P2) compared to the non-diabetic group with a $\mathrm{p}$ value $<0.001$.

Conclusion: VT of the upper limb is higher in individuals with type II diabetes mellitus as compared to non-diabetic individuals.

Keywords: Vibration threshold, ULNT1, Diabetes mellitus

Journal of Multidisciplinary Research in Healthcare

Vol-3, No-2, April 2017 pp. 79-86 


\section{Reddy, RS 1. INTRODUCTION:}

Diabetes mellitus is a group of metabolic syndrome which is characterized by increased levels of glucose in the blood resulting from impaired insulin secretion, insulin action, or both [1]. Type II diabetes mellitus is most common form which is a disease of insulin resistance that usually has relative (rather than absolute) insulin deficiency [1]. Earliest functional change in diabetic nerve is change in axonal excitability due to alterations in ion conductance of axon membrane due to metabolic processes directly affecting the nerves, microvascular abnormalities of the endoneurium and autoimmune inflammation [2]. Four main mechanisms have been postulated to underlie the pathogenesis of nerve pathology in diabetes mellitus, which are metabolic processes directly affecting nerve fibres, endoneurial microvascular disease, autoimmune inflammation and deranged neurotrophic support $[2,3]$. These changes are due to these effects of elevated levels of glucose which involves the peripheral nerve in type II diabetes mellitus subjects. It has been documented that most of type II diabetic patients have peripheral neuropathy [4]. Among the nerves, there is a tendency of the large diameter nerve fibers that mediate sense of vibration to get involved first in diabetes mellitus [5].

Neurodynamic tests involve sequential limb movements that are employed to elicit the connection between physiological and mechanical types of different mechanisms [6,7]. The main ambition of using these different tests in assessment of a nerve function is to mechanically stimulate and mobilize neural tissues in order to get an expression of their mobility and sensitivity to mechanical stresses so as to arouse the physiological responses $[7,8]$. In order to assess the upper limb nerve function, the standard upper limb neurodynamic test 1 (ULNT1) is usually used as it evokes symptoms of distribution of the median nerve because the forces generated by this test are biased towards this structure [8]. There are various techniques of assessing the conductivity of nerve such as nerve conduction velocity that basically assesses the motor and sensory aspects of the nerve. Whereas, vibration threshold (VT) reflects particular function of the peripheral nervous system especially the somatosensory pathway $[8,9]$.

Type II diabetes mellitus patients are showed to affect the different multimodal systems (sensory, reflex and motor) in distal extremities [10, 11]. Mechanosensitivity in diabetes mellitus patients should be considered as an essential inclusion in the assessment to predict the extent of involvement of the nerve [11]. Studies have also been done to determine the VTin lower limb in normal individuals but there is scanty literature available in comparison of the VTin the upper limb in type II diabetes mellitus patients when compared with non diabetic subjects. 


\section{METHODS}

\subsection{Study Design}

Pre-test post-test 2-group cross sectional study design was conductedin department of Physical therapy, King Khalid University, Abha, Saudi Arabia.

\subsection{Subject Selection}

Thirty subjects with type II diabetes with age of 55.60 ( $\mathrm{SD} \pm 9.79$ )were recruited from the outpatient university physiotherapy clinic who were referred from registered practitioner. All subjectswere evaluated by experienced physical therapist in the field of diabetes and musculoskeletal examination, and the subjects who met inclusion criteria were enrolled into the study. Diabetic subjects with clinical signs of neuropathywere excluded from the study. Recruitment of age matched normal subjects was done through advertisement in the King Khalid University for voluntary participation in the study. The subjects were included if are aged between 30 to 70 years, have had no H/odiabetes, upper limb disorders, Cervico-brachial pain syndrome, acute inflammatory/ demyelinating diseases, any recent surgeries in upper limb. 30control subjects were recruited by age to ensure a similar match to the diabetic group. The mean age of the subjects was $53.43 \pm 9.96$. All the subjectswerefamiliarized with the study equipment and testing procedure in the first session prior to the actual testing session. All the subjects read, understood and signed an informed consent prior to the commencement of the study and University ethical committee approved the study.

\section{MEASUREMENT OF VIBRATION THRESHOLD (VT)}

VT was measured by the same tester at the baseline for both the groups using a bioesthesiometer capable of delivering a vibration of $100 \mathrm{~Hz}$. The subjects were made to sit comfortably on a chair with hand and arm placed completely on the pillow. The probe of the Vibrometer was placed at the pulp of the distal phalanx of the thumb [12]. Either right or left hand was tested. The subjects were shielded from the Vibrometer display during testing to avoid any bias. At baseline, tester 1 first increased the vibration to a point where the subject perceived the stimulus. This was taken as appearance of vibration. Then the intensity was further increased and slowly reduced until they identified the disappearance of the stimulus. This measurement was done thrice and the average of the six values was taken as the vibration threshold.

After the VT was taken at the baseline, the tester performed the ULNT1 (adopted from M. Shacklock [8] for each individual. For this, a pressure
Comparison

of Vibration

Threshold of Upper

Limb During

Upper Limb

Neurodynamic Test

1 in Individuals with and without Type II Diabetes

Mellitus

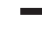



the shoulder was abducted to 90-110 degrees followed by complete external rotation, forearm supination, wrist and finger extension. The last component of ULNT1 was elbow extension and elbow extension value was recorded using universal goniometer as a measure of mechanosensitivity. During the sequence of the ULNT1, the occurrence of the first response of elbow extension i.e. pain considered as P1 was noted. The angle of its occurrence was measured with the universal Goniometer and VT at this position in the same manner as that of baseline was taken for both the groups by the tester 2 . The next occurrence of the symptom i.e. P2 at which any further movement was intolerable was noted. The corresponding elbow extension angle of P2 was measured. The range of elbow extension was reduced until the feeling of discomfort disappeared and VT was measured at this point for both the groups by the tester 2 . The reduction of elbow extension was adopted to avoid the masking of pain for perception of vibration. The measurement of VTwas measured for both diabetic individuals and age matched normal individuals.

\section{DATA ANALYSIS AND RESULTS:}

SPSS 20.0 version for windows software was used to analyse the data. To be considered statistically significant the $\mathrm{p}$ value was set at $\leq 0.005$. Demographic data regarding the age (yrs.), sex and duration of individuals with type II diabetes mellitus and non-diabetic individuals aresummarizedin table no. 1

Table no. 2 and Figure 1 shows the comparison of the VT between the diabetic and the non-diabetic group at three levels i.e. VT at baseline, VT at $\mathrm{P} 1$ and VT at short of P2. There was a statistical significant difference between the VT of diabetic and non-diabetic group at the three levels with a p value < 0.001 . This states that the VT was found to be raised in the diabetic group at all the three levels compared to the non-diabetic group. Thus, VT of the upper limb is higher in individuals with type II diabetes mellitus as compared to nondiabetic individuals.

Table 1: Study population characteristics $[n=60]($ Mean \pm SD).

\begin{tabular}{lll}
\hline & Diabetic group $\mathrm{n}=30$ & Control group $\mathrm{n}=30$ \\
\hline Age $(\mathrm{yrs})$ & $55.60 \pm 9.79$ & $53.43 \pm 9.96$ \\
Sex Male: female & $19: 11$ & $15: 15$ \\
$\begin{array}{l}\text { Duration of diabetes } \\
\text { (yrs.) median (IQR) }\end{array}$ & $5.50(1.75-10.50)$ & - \\
\hline
\end{tabular}


Table 2: Comparison of Vibration threshold between and within groups.

\begin{tabular}{llcl}
\hline Outcome measure & $\begin{array}{l}\text { Diabetic group } \\
\text { Mean } \pm \text { SD }\end{array}$ & $\begin{array}{l}\text { Control group } \\
\text { Mean } \pm \text { SD }\end{array}$ & p value \\
\hline VT baseline & $6.06 \pm 1.98$ & $3.72 \pm 1.08$ & \\
VT at P1 & $6.24 \pm 2.16$ & $4.04 \pm 1.24$ & $\begin{array}{l}\text { Between groups: } \\
\mathrm{p}<0.001\end{array}$ \\
VT at less than P2 & $6.46 \pm 2.13$ & $3.99 \pm 1.40$ & \\
p value & \multicolumn{3}{c}{ Within groups 0.755} \\
\hline
\end{tabular}

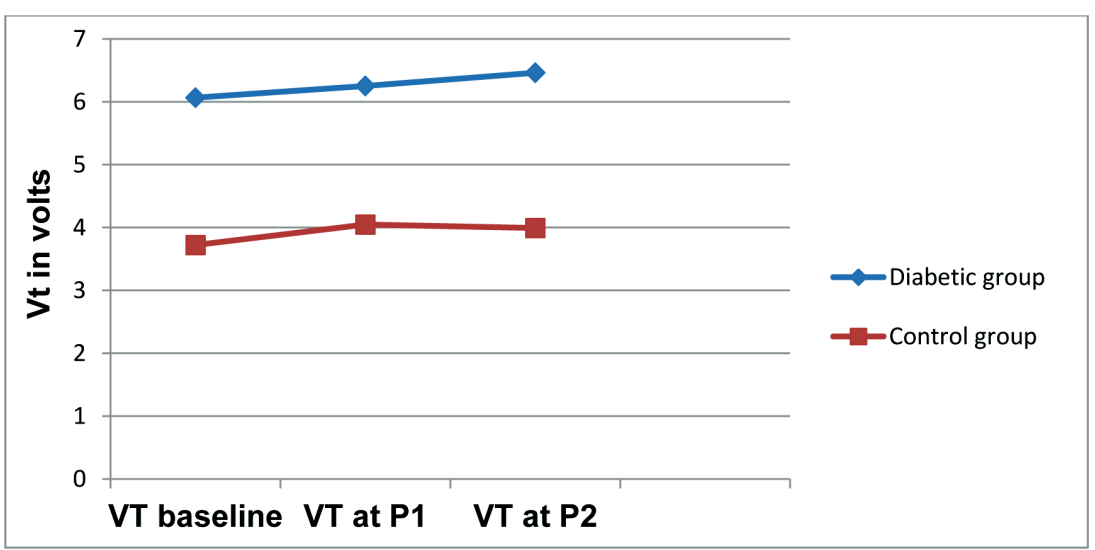

Figure 1: Trend line showing Vibration Threshold difference between groups and within group.

\section{DISCUSSION}

Our study aimed at comparing the VTof the upper limb during ULNT1 in individuals with type II diabetes mellitus and non-diabetic individuals. As per the results, the VTwas found to be increased in the individuals with type II diabetes mellitus as compared to the non-diabetic individuals.

VTis a measure of conductivity i.e. a function of the axon in conducting the impulse from the external receptor [13]. Thus, alteration of the VTin type II diabetic individuals may be due various reasons. Recent studies show endoneural hypoxia and reduced neural perfusionare reduced in human
Comparison of Vibration Threshold of Upper Limb During Upper Limb Neurodynamic Test 1 in Individuals with and without Type II Diabetes

Mellitus

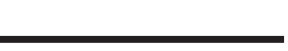


and animal models with diabetes. Investigations on subjects with diabetic neuropathy showed structural changes in nerve microvasculature such as basement membrane thickening, endothelial cell hyperplasia and pericyte degeneration etc. ${ }^{14-16}$. Reduced endoneural perfusion is also contributed by arterio-venous shunting. These changes strongly correlate between nerve pathology and vascular changes. Vasa nervorum changes that occur early are caused by diabetes mellitus insult, because of such the balance between vasodilator and vasoconstrictor are altered [14]. All the above said findings might have contributed for increase in VT findings in diabetic group subjects when compared to non-diabetic subjects.

The findings of our study regarding the VTare in contrast with the study done by David A Gebler et al [17]. They conducted a study to check the vibratory and thermal thresholds in normal and diabetic individuals using aThermal Sensitivity Tester andOptacon Tactile Tester (OTT). They did not find the vibratory and thermal threshold of diabetic subjects to be different from the asymptomatic / normal individuals. Our study findings cannot be compared with these study findings, as the methodological considerations are different from our study. A Gebler et al [17] study showed that the thermal and vibratory thresholds were found to be increasedin diabetic individuals with neuropathy [17] but our study did not include subjects with neuropathy. Further studies are required to see if there will be differences in VT in subjects with diabetic neuropathy and non-neuropathic subjects.

The limitations of our study include that the study sample was not calculated and the sample of 30 is less to compare between diabetics and non-diabetics.

\section{CONCLUSION}

We conclude that VTin subjects with type 2 diabetes mellitus is increased when compared to asymptomatic individuals. Physical therapists should consider this finding during evaluation and management of patients with type 11 diabetes mellitus.

\section{REFERENCES}

[1] Periféricas ND, Morfométrica UVG. (2010). Diabetic peripheral neuropathies: a morphometric overview. Int. j. morphol. 28(1), 51-64.

[2] POP-BUSUI R, Sullivan K, Feldman E. (2007). Diabetes and the Nervous System. Neurology and General Medicine. 383-408.

[3] Ranzani R, Abraham A, Chakravarthy R, Lakshmi S. (2012). Indigenous uncoated and hydroxyapatite coated commercially pure titanium foils for guided 
bone regeneration in defect sites of implants-an in vitro study. ISSN 0975-5241 IC Value of Journal: 4.18. 4(17), 112.

[4] Murinson BB, Chaudhry V. (2014). Metabolic and endocrine neuropathies. Neuromuscular Disorders in Clinical Practice: Springer; 693-702. https://doi.org/10.1007/978-1-4614-6567-6_33

[5] Behnam-Rassouli M, Ghayour M, Ghayour N. (2010). Microvascular complications of diabetes. J. Biol. Sci. 10, 411-423. https://doi.org/10.3923/jbs.2010.411.423

[6] Walsh MT. (2005). Upper limb neural tension testing and mobilization: fact, fiction, and a practical approach. J. Hand Ther. 18(2), 241-258. https://doi.org/10.1197/j.jht.2005.02.010

[7] McLaren N. An investigation into normative responses for the upper limb neurodynamic test with radial nerve bias 2013 .

[8] Shacklock M. Clinical neurodynamics: a new system of musculoskeletal treatment: Elsevier Health Sciences; 2005.

[9] Laursen LH, Jepsen JR, Sjøgaard G. (2006). Vibrotactile sense in patients with different upper limb disorders compared with a control group. Int. Arch. Occup. Environ. Health. 79(7), 593-601. https://doi.org/10.1007/s00420-006-0094-7

[10] Van Deursen R, Simoneau GG. (1999). Foot and ankle sensory neuropathy, proprioception, and postural stability. J. Orthop. Sports Phys. Ther. 29(12), 718726. https://doi.org/10.2519/jospt.1999.29.12.718

[11] Boyd BS, Wanek L, Gray AT, Topp KS. (2010). Mechanosensitivity during lower extremity neurodynamic testing is diminished in individuals with Type 2 Diabetes Mellitus and peripheral neuropathy: a cross sectional study. BMC Neurol. 10(1),75. https://doi.org/10.1186/1471-2377-10-75

[12] Ridehalgh C, Greening J, Petty NJ. (2005). Effect of straight leg raise examination and treatment on vibration thresholds in the lower limb: a pilot study in asymptomatic subjects. Man Ther. 10(2), 136-143. https://doi.org/10.1016/j.math.2004.08.008

[13] Mountcastle VB. (1967). The problem of sensing and the neural coding of sensory events. The neurosciences. 1, 393-408.

[14] Cameron N, Eaton S, Cotter M, Tesfaye S. (2001). Vascular factors and metabolic interactions in the pathogenesis of diabetic neuropathy. Diabetologia. 44(11), 1973-1988. https://doi.org/10.1007/s001250100001

[15] Suzuki C, Ozaki I, Tanosaki M, Baba M. (2000). Peripheral and central conduction abnormalities in diabetes mellitus. J. Peripher. Nerv. Syst. 5(3), 176-176.https:// doi.org/10.1046/j.1529-8027.2000abstracts-26.x

[16] Estrella JS, Nelson RN, Sturges B, et al. (2008). Endoneurial microvascular pathology in feline diabetic neuropathy. Microvasc. Res. 75(3), 403-410.

https://doi.org/10.1016/j.mvr.2007.12.002
Comparison

of Vibration

Threshold of Upper

Limb During

Upper Limb

Neurodynamic Test

1 in Individuals with and without Type II Diabetes

Mellitus

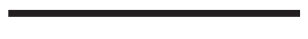


Reddy, RS

[17] Gelber DA, Pfeifer MA, Broadstone VL, et al. (1995). Components of variance for vibratory and thermal threshold testing in normal and diabetic subjects. J. Diabetes Complications. 9(3), 170-176.

https://doi.org/10.1016/1056-8727(94)00042-M 